\title{
Improvement of a Propulsion Equipment with a Supersonic Nozzle for Single Pulse Detonation
}

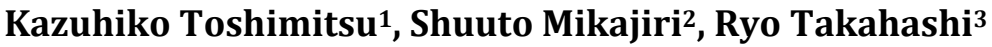 \\ ${ }^{1}$ Department of Mechanical Engineering, Oita National College of Technology, Oita, Japan \\ ${ }^{2}$ Mechanical-Environmental System Engineering Major, Oita National College of Technology, Oita, Japan \\ ${ }^{3}$ Department of Computer Science and System Engineering, Kyushu Institute of Technology, Kitakyushu, Japan \\ Email: tosimitu@oita-ct.ac.jp
}

Received 27 October 2014; revised 20 November 2014; accepted 18 December 2014

Copyright (C) 2014 by authors and Scientific Research Publishing Inc.

This work is licensed under the Creative Commons Attribution International License (CC BY).

http://creativecommons.org/licenses/by/4.0/

(c) (i) Open Access

\begin{abstract}
A pulse detonation engine (PDE) is one of candidates of aerospace engines for supersonic cruse. In the paper, a supersonic nozzle ejector is designed to increase thrust of single pulse detonation for methane-oxygen and hydrogen-oxygen mixtures. The design method is based on the conventional characteristic method and inlet condition is averaged value of detonations of methane-oxygen and hydrogen-oxygen mixtures. Comparison of thrusts with a design nozzle and no nozzle (straighttype) is conducted to ensure the designed nozzle performance. Furthermore, the flow velocity, temperature and velocity of the designed nozzle are calculated to ensure its appropriateness with the commercial software ANSYS CFX. Consequently, we succeed in increasing the thrusts of the single pulse detonation with the nozzle, which are 1.4 and 2.0 times as large as ones of straighttype for methane-oxygen and hydrogen-oxygen mixtures respectively.
\end{abstract}

\section{Keywords}

Thruster, Detonation, Impulse, Supersonic Flow, Method of Characteristics, CFD, Nozzle

\section{Introduction}

The increase thrust performance for a space-plane and a rocket is important. In particular, the development of high-efficiency propulsion is required in supersonic cruising. According to the background, a pulse detonation engine (PDE) was proposed on 1990s, and PDE has been studied in many institutions [1] [2].

Our final goal is to design, manufacture and operate PDE for the space and air-breathing propulsion devices at 
laboratory level.

In order to increase the thrust of PDE, we will conduct to design and manufacture an optimum supersonic nozzle, which is based on the characteristics method of the supersonic nozzle for single pulse detonation in the paper. Furthermore, performance of the nozzle ejector is investigated by experiment and CFD analysis to validate appropriateness of the design.

\section{Experimental Procedure}

\subsection{Experimental Apparatus}

Figure 1 shows a schematic diagram of the entire experimental apparatus. The total length, inner diameter and tube thickness of the detonation tube (DT tube) are $1000 \mathrm{~mm}, 30 \mathrm{~mm}$ and $10 \mathrm{~mm}$, respectively. DT tube is suspended by the two stainless wires of diameter $1 \mathrm{~mm}$, and oscillates freely by single impulsive detonation.

Its impulse can be calculated from Equation (1) of the ballistic pendulum method proposed by Yatsufusa et al. [3].

$$
I=m \cdot x \cdot \mathrm{e}^{\frac{\pi}{2} \varsigma} \cdot \frac{2 \pi}{T}
$$

Here, $m, x, \varsigma$ and $T$ denote the suspended weight [kg], the maximum displacement from the neutral position [m], the damping coefficient and the oscillation period [s], respectively.

\subsection{Design of the Axisymmetric Supersonic Nozzle}

An axisymmetric supersonic nozzle is designed through the characteristic method based in Foelsch [4]. Figure 2 schematically illustrates the characteristics method for the nozzle. It is assumed that flow is steady and isentropic without boundary layer. The thrust is increased by attaching the nozzle at the outlet of DT tube.

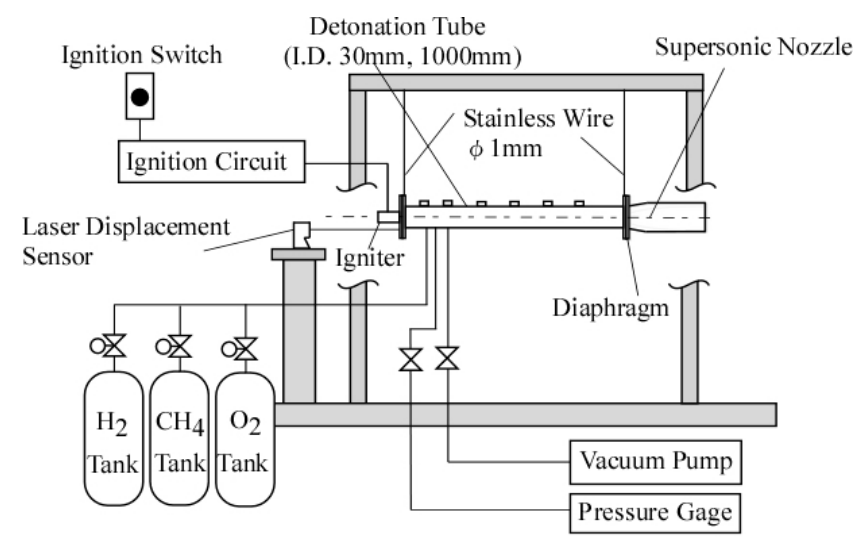

Figure 1. Experimental apparatus to measure thrust on the basis of ballistic pendulum method.

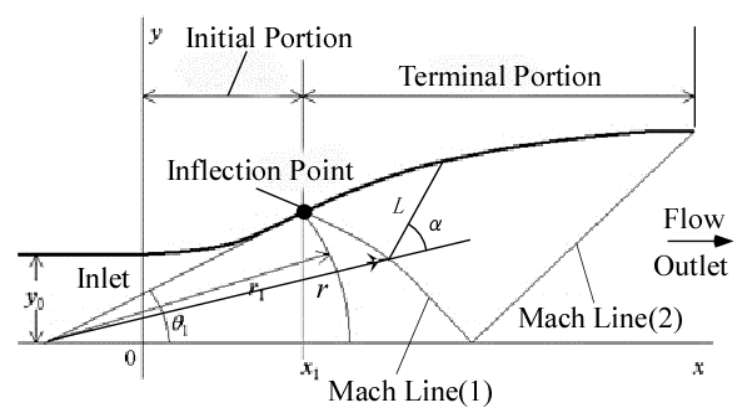

Figure 2. Method of characteristic of axisymmetric supersonic nozzle flow. 


\subsection{Design Conditions of Nozzle}

Table 1 shows the design conditions. Nozzle inlet conditions are the average values of the detonation combustion states of both gas mixtures of $\mathrm{H}_{2}-\mathrm{O}_{2}$ and $\mathrm{CH}_{4}-\mathrm{O}_{2}$ for equivalence ratio $\varphi$ is one. The specific heat ratio of the combustion mixture is assumed as 1.31. Mach number, static pressure and static temperature at the nozzle inlet are $1.7(700 \mathrm{~m} / \mathrm{s}), 354.6 \mathrm{kPa}$ and $1530 \mathrm{~K}$, respectively. The inlet diameter of the nozzle is $30 \mathrm{~mm}$ as same as the inner diameter of the detonation tube. Furthermore, outlet pressure $p_{e}$ is set as atmospheric pressure. Other outlet values are automatically determined. Here, the nozzle profile is shown in Figure 3.

\subsection{CFD Analysis}

In order to validate the previous design, CFD analysis of the nozzle internal flow is conducted using commercial software ANSYS CFX Ver.14.

Table 1 shows the calculation conditions. Turbulent model of the calculation is eddy-viscosity model that includes vortex scale and turbulent intensity are $2.0 \mathrm{~mm}$ and $5 \%$ respectively.

Figure 4 shows computational domain which is consisted of non-structured mesh with 2,701,865 tetrahedron elements and 472,930 nodes.

The calculated pressure, temperature, velocity distribution are illustrated in Figure 5. It is ensured that the exit velocity and pressure are substantially uniform on the nozzle exit surface. In addition, the boundary layer is not so thick. As the results, we can consider that the nozzle design is appropriate.

\section{Experimental Results}

We will make sure the designed nozzle performance though comparisons of impulse and specific impulse with the nozzle and no nozzle (i.e. exhaust straightly).

\subsection{Impulse}

Figure 6 shows impulses with nozzle and no nozzle, which are varying the equivalence ratio of $\mathrm{CH}_{4}-\mathrm{O}_{2}$ and $\mathrm{H}_{2}-\mathrm{O}_{2}$ gas mixture. Since all impulse is constant with varying $\varphi$ from 0.8 to 1.8. Thus it does not depend on equivalence ratio. The impulses with $\mathrm{CH}_{4}-\mathrm{O}_{2}$ and $\mathrm{H}_{2}-\mathrm{O}_{2}$ mixtures with nozzle are about as 1.4 and 2 times as the no nozzle case respectively.

\begin{tabular}{ccc} 
Table 1. Conditions for characteristic method. & \\
\hline & Designed supersonic nozzle & \\
\hline Specific heat ratio & $\gamma$ & 1.31 \\
Total pressure & $p_{0 i}$ & $2000 \mathrm{kPa}$ \\
Total temperature & $T_{0 i}$ & $2500 \mathrm{~K}$ \\
\hline Mach number & Inlet & \\
Pressure & $M_{i}$ & 1.7 \\
Temperature & $p_{i}$ & $354.6 \mathrm{kPa}$ \\
Diameter of nozzle & $T_{i}$ & $1530 \mathrm{~K}$ \\
Cross sectional aria & $d_{i}$ & $30.0 \mathrm{~mm}$ \\
& $A_{i}$ & $706.9 \mathrm{~mm}{ }^{2}$ \\
\hline Mach number & Outlet & 3.7 \\
Pressure & $M_{e}$ & $101.3 \mathrm{kPa}$ \\
Temperature & $p_{e}$ & $400 \mathrm{~K}$ \\
Diameter of nozzle & $T_{e}$ & $83.8 \mathrm{~mm}$ \\
Cross sectional aria & $d_{e}$ & $5515.4 \mathrm{~mm}^{2}$ \\
\hline
\end{tabular}




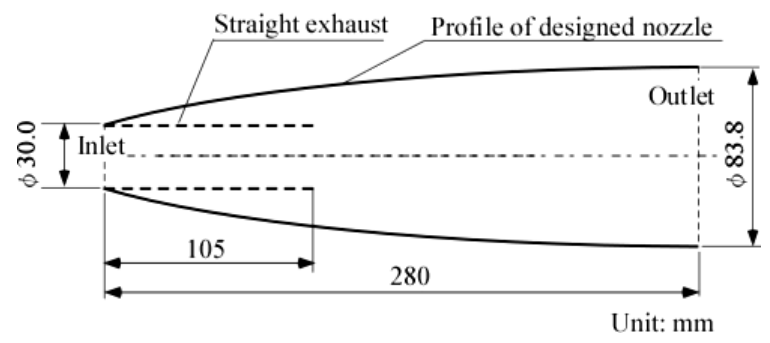

Figure 3. Designed supersonic nozzle profile.

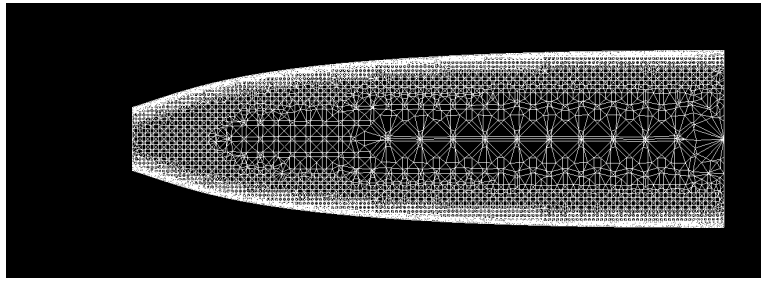

Figure 4. Computational mesh on center plane.
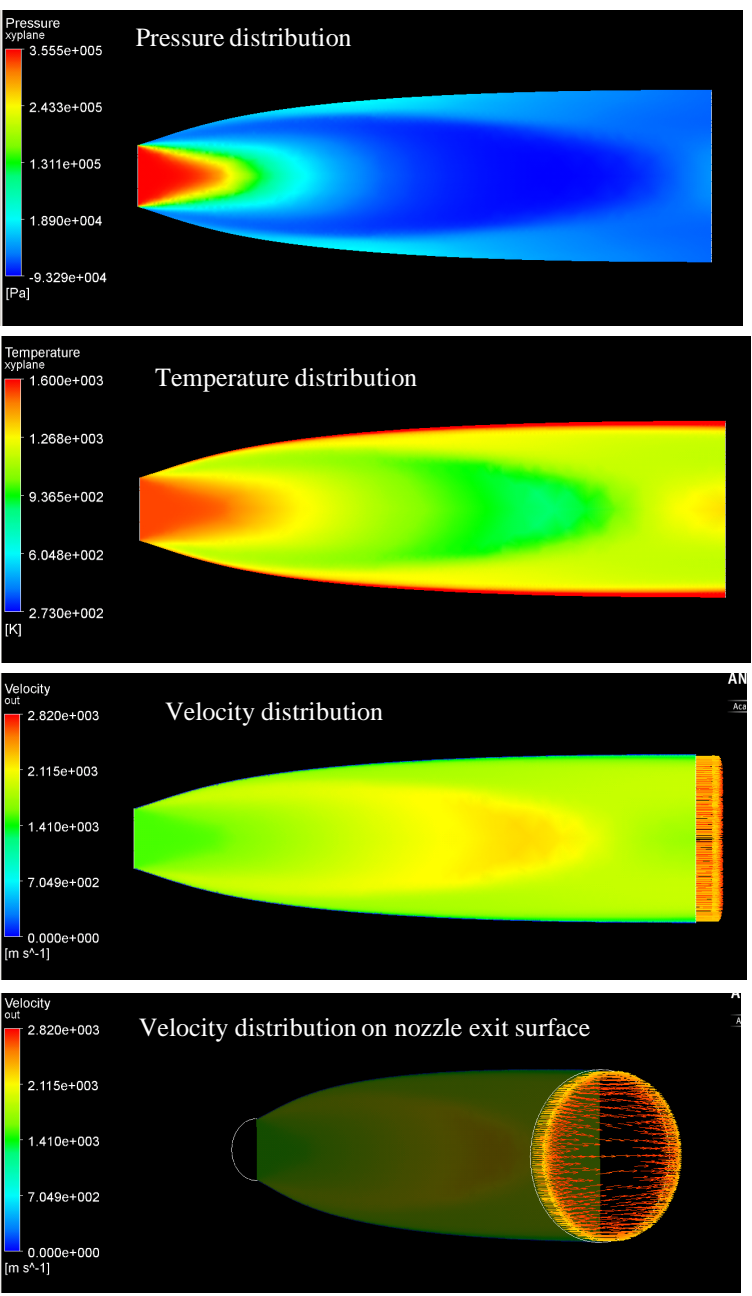

Figure 5. CFD analysis results of the supersonic nozzle with pressure, temperature, velocity and velocity on nozzle exit surface. 


\subsection{Specific Impulse}

The specific impulse $I_{S P}$ is defined by Equation (2). It represents continuous time which thrust can be maintained as $1 \mathrm{~N}$ with propellant mass $1 \mathrm{~kg}$.

$$
I_{S P}=\frac{F_{t}}{\dot{m} g}=\frac{I}{m g}
$$

Here, $F_{t}, I$ and $m$ mean thrust, impulse and combustible propellant mass, respectively. We should mention that $m$ is defined as fuel only for air-breathing engine or fuel plus oxidizer for rocket engine. The former and latter $I_{S P}$ are called as "fuel-base" and "mixture-base" specific impulses.

The experimental specific impulse with varying equivalence ratio $\varphi$ of $\mathrm{CH}_{4}-\mathrm{O}_{2}$ and $\mathrm{H}_{2}-\mathrm{O}_{2}$ gas mixtures are shown in Figure 7 to Figure 10. The fuel-base $I_{S P}$ decreases with increasing $\varphi$ of both mixtures of $\mathrm{CH}_{4}-\mathrm{O}_{2}$ and $\mathrm{H}_{2}-\mathrm{O}_{2}$. In particular, specific impulse is large at lean fuel combustion with the nozzle. Namely, the maximum specific impulses of $\mathrm{CH}_{4}-\mathrm{O}_{2}$ and $\mathrm{H}_{2}-\mathrm{O}_{2}$ are $1463 \mathrm{~s}$ at $\varphi=0.6$ and $3096 \mathrm{~s}$ at $\varphi=0.39$ respectively. This means that $I_{S P}$ of $\mathrm{CH}_{4}-\mathrm{O}_{2}$ and $\mathrm{H}_{2}-\mathrm{O}_{2}$ correspond to a ramjet engine (500 - $1500 \mathrm{~s}$ ) and a turbo-jet engine (2300 s - 2900 s), respectively.

We will discuss about the mixture-base $I_{S P}$ for rocket engine as follows. The mixture-base $I_{S P}$ of $\mathrm{CH}_{4}-\mathrm{O}_{2}$ show almost constant value for the equivalence ratio $0.8<\varphi<2.0$ (except $\varphi=0.6$ and 2.2), and $I_{S P}$ with nozzle is about as 1.4 times as one with no nozzle. In particular, $I_{S P}$ of no nozzle slightly decreases at $\varphi=2.2$, while $I_{S P}$ with the nozzle does not decrease. This is concerned about combustion state. Here, we should consider that the range of detonation combustion is $0.8<\varphi<2.0$ and one of non-detonation combustion is $\varphi=2.2$ with $\mathrm{CH}_{4}-\mathrm{O}_{2}$, so that the nozzle can operate as an effective thrust generator for both combustion states.

The specific impulse of $\mathrm{H}_{2}-\mathrm{O}_{2}$ is increased in proportion to equivalent ratio.

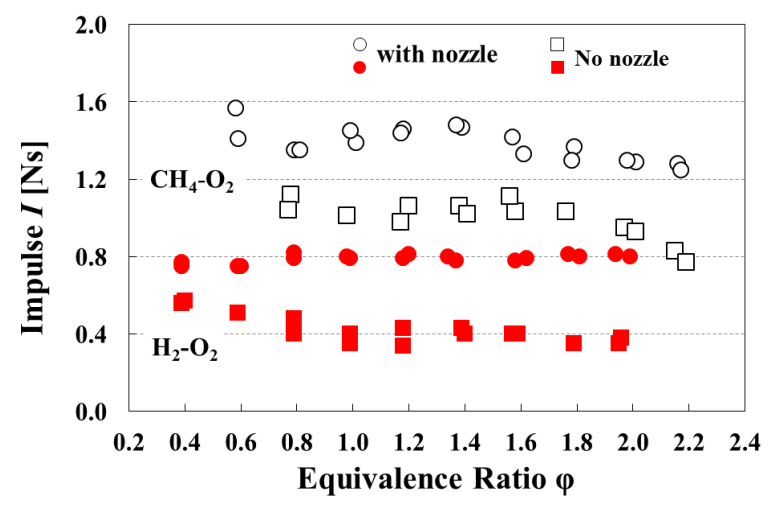

Figure 6. Effects of the nozzle, mixture gases and equivalence ratio on impulse.

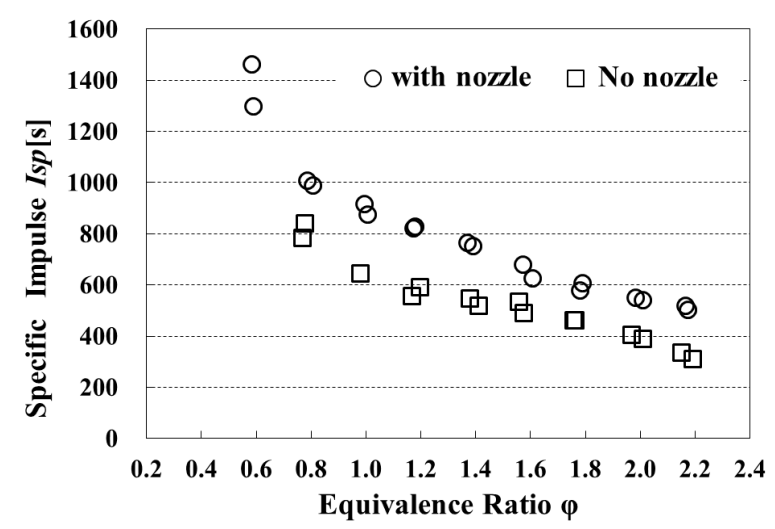

Figure 7. Effects of the nozzle and equivalence ratio on fuel-base specific impulse with $\mathrm{CH}_{4}-\mathrm{O}_{2}$ mixture. 


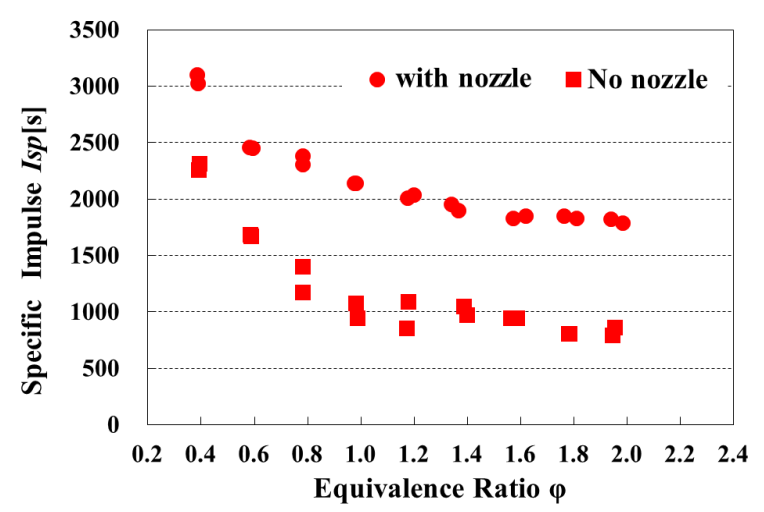

Figure 8. Effects of the nozzle and equivalence ratio on fuel-base specific impulse with $\mathrm{H}_{2}-\mathrm{O}_{2}$ mixture.

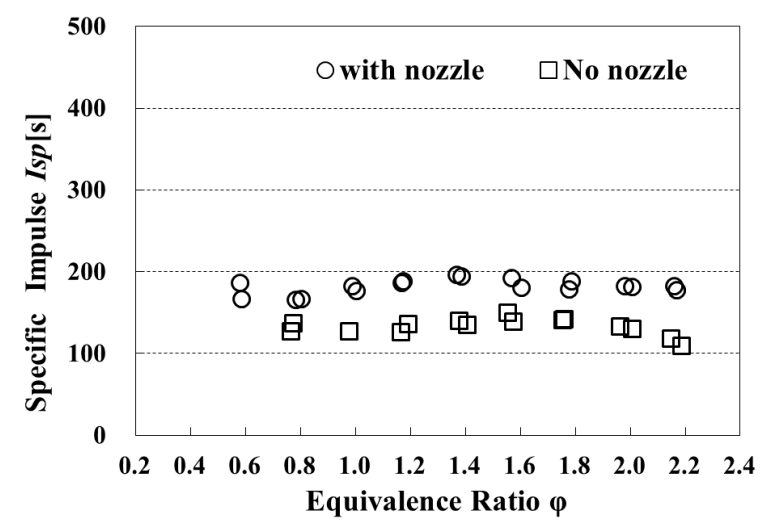

Figure 9. Effects of the nozzle and equivalence ratio on mixture-base specific impulse with $\mathrm{CH}_{4}-\mathrm{O}_{2}$ mixture.

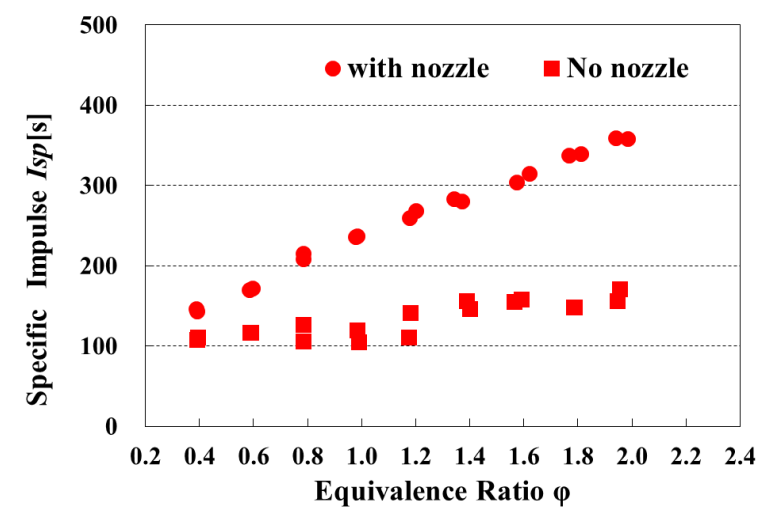

Figure 10. Effects of the nozzle and equivalence ratio on mixture-base specific impulse with $\mathrm{H}_{2}-\mathrm{O}_{2}$ mixture.

\section{Conclusions}

In the study, we design and manufacture a supersonic nozzle through method of characteristics to increase thrust of single pulse detonation. In order to confirm the effectiveness of the nozzle, we compare the impulse and specific impulse with nozzle and no nozzle (straight exhaust) for methane-oxygen and hydrogen-oxygen gas mixtures through the ballistic pendulum method. The results obtained are as follows.

- The impulses of $\mathrm{CH}_{4}-\mathrm{O}_{2}$ and $\mathrm{H}_{2}-\mathrm{O}_{2}$ gas mixtures with the nozzle are about as 1.4 and 2 times as the straight exhaust respectively. Thus, the present design is useful to increase thrust by the detonation. 
- The fuel-base specific impulses of $\mathrm{CH}_{4}-\mathrm{O}_{2}$ and $\mathrm{H}_{2}-\mathrm{O}_{2}$ gas mixtures decrease with increasing equivalence ratio. As the result, lean combustion is suitable for large fuel-base specific impulse.

- The designed nozzle can keep a constant value of the impulse and mixture-base specific impulse in $\mathrm{CH}_{4}-\mathrm{O}_{2}$ for detonation and non-detonation combustions. Hence, it is an effective thrust generator for the combustion states.

\section{References}

[1] Eidelman, S., Grossmann, W. and Lottati, I. (1991) Review of Propulsion Applications and Numerical Simulations of the Pulsed Detonation Engine Concept. Journal of Propulsion, 7, 857-865. http://dx.doi.org/10.2514/3.23402

[2] Kailasanath, K. (2001) A Review of PDE Research-Performance Estimates. The 39th Aerospace Sciences Meeting \& Exhibit, AIAA Paper-2001-0474.

[3] Yatsufusa, T., Endo, T. and Taki, S. (2008) Effect of Initiator Conditions on Detonation Initiation and Impulse in Pulse-Detonation Engines. Transactions of Mechanical Engineer, 74, 2055-2062. (In Japanese) http://dx.doi.org/10.1299/kikaib.74.2055

[4] Crown, B.J.C. (1948) Supersonic Nozzle Design. NACT Technical Note, No. 1651. 
Scientific Research Publishing (SCIRP) is one of the largest Open Access journal publishers. It is currently publishing more than 200 open access, online, peer-reviewed journals covering a wide range of academic disciplines. SCIRP serves the worldwide academic communities and contributes to the progress and application of science with its publication.

Other selected journals from SCIRP are listed as below. Submit your manuscript to us via either submit@scirp.org or Online Submission Portal.
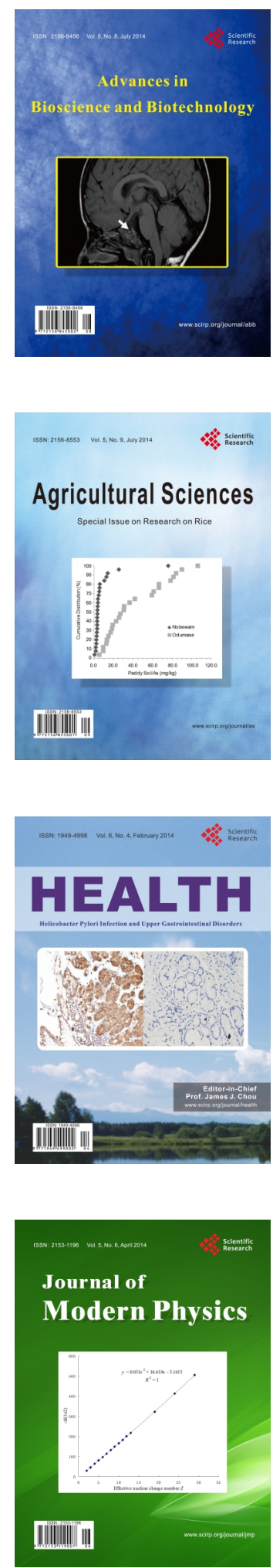
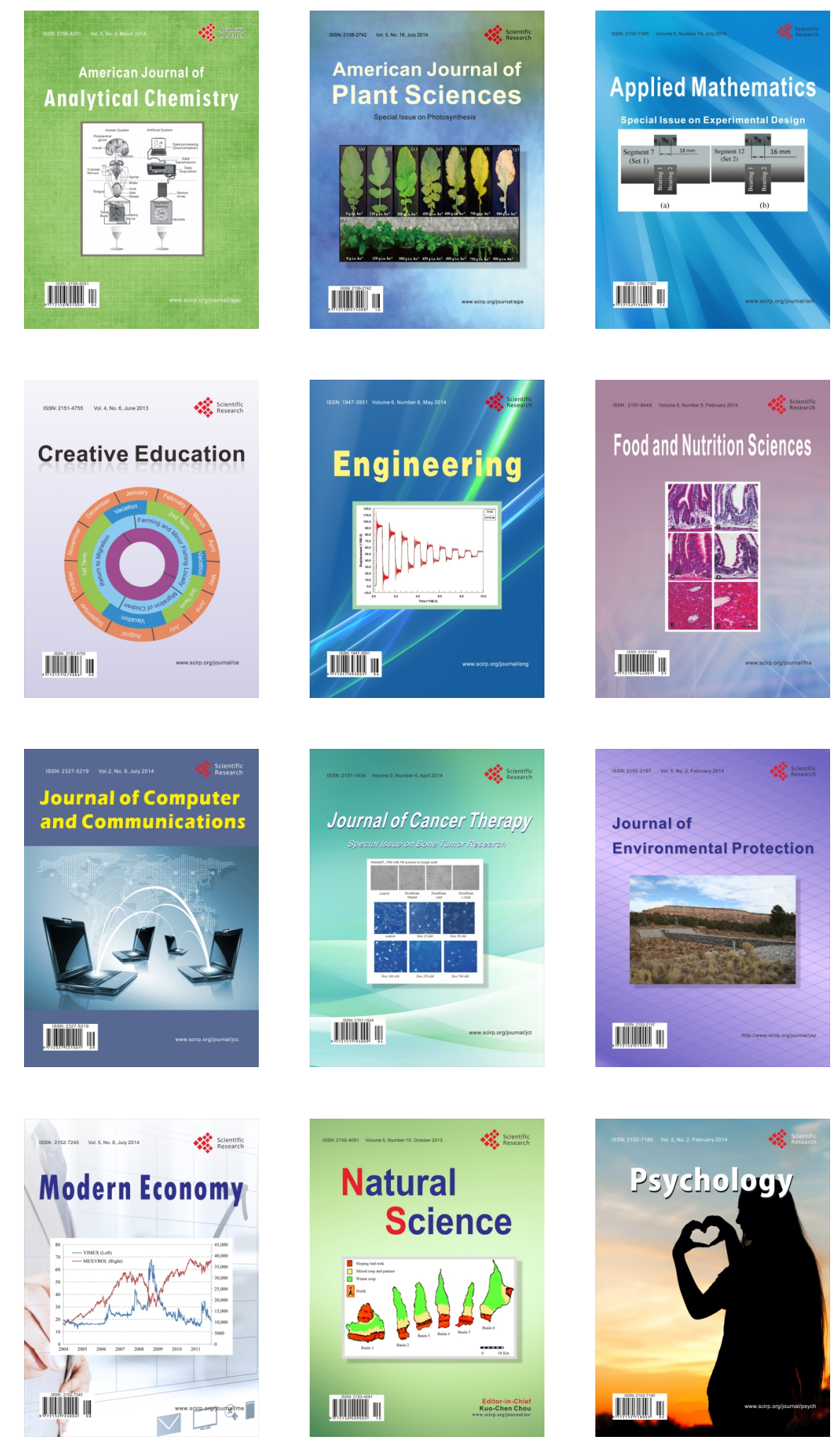